\title{
De Narciso Aréstegui a Antonio Cornejo Polar (Antecedentes contextuales del concepto de heterogeneidad literaria)
}

Rolando Álvarez
Universidad de Guanajuato

Resumen

En este trabajo se hace una revisión de algunos autores y obras que en Perú pueden señalarse como antecedentes directos del concepto de heterogeneidad literaria formulado por Antonio Cornejo Polar.

Palabras clave: heterogeneidad, historia, realidad, peruanismo, ficción.

Abstract

In this paper we review some authors and works that in Peru can be identified as direct antecedents of the concept of literary heterogeneity formulated by Antonio Cornejo Polar.

Keywords: Heterogeneity, History, Reality, Peruvianism, Fiction. 
L a heterogeneidad, entendida como la relación que se produce en el encuentro de dos series culturales que no llegan a conformar un estado de transculturación o mestizaje, es la categoría definitoria de un sector significativo de la narrativa del Perú. Ya en las crónicas de conquista y en las crónicas o "corónicas" coloniales encontramos que es un factor omnipresente, pues son escritos que dan cuenta de la "realidad" inmediata a aquellos autores, ibéricos o americanos, en los que priva el principio de "ser ajenos" a las otredades que el universo "relatado" contiene y que desde esta ajenidad es referido en sus textos sin importar el género de tales relatos (históricos, administrativos, utópicos, mestizos, conventuales o de visitación); ya se trate del andaluz Bernabé Cobo o del cuzqueño Pablo José de Arriaga (Vid. Marzal, 1993).

A lo largo de la historia del Perú — conjuntamente a los textos de orden crítico, histórico o político- las obras de ficción han servido para patentizar la heterogeneidad cultural del país, acusando la postura ideológica de sus autores y las corrientes de pensamiento que circulan en su momento. Para efecto de este trabajo, se toman como línea de partida dos novelas del siglo XIX: El padre Horán (1848), de Narciso Aréstegui (1820?-1869), y Aves sin nido (1889), de Clorinda Matto de Turner (1852-1909). A partir de los elementos que estas obras ofrecen en materia de heterogeneidad, pasaremos a revisitar a otros autores que, desde la literatura, el pensamiento o la producción artística —incluso no literaria-, evidencian la presencia de la heterogeneidad como categoría sustantiva de su obra y de un sector del quehacer literario y artístico en el Perú. Autores que anteceden a Antonio Cornejo Polar y nutren su pensamiento, nombres que van desde los ya citados Narciso Aréstegui y Clorinda Matto de Turner hasta José María Arguedas y Alberto Escobar, pasando por Manuel González Prada, Francisco Lazo, José Carlos Mariategui o Gamaliel Churata. El objetivo es revisitar bajo la luz del pensamiento de Cornejo Polar y con una 
intención cronológica que permita vislumbrar vasos comunicantes entre los actores de un escenario histórico y cultural múltiple. En suma, se intenta trazar un horizonte para que el concepto cornejista de heterogeneidad revele su entramado histórico.

El padre Horán, de Narciso Aréstegui, es considerada la primera novela peruana. ${ }^{1}$ Se publicó por entregas en 1848 en el diario limeño El comercio. El texto evidencia que el autor se sirve del género literario como instrumento de crítica social. Situada su anécdota en el Cuzco, la obra refleja la conformación de la sociedad y se declara a favor de los indios. Es notable cómo se trasluce en el texto la heterogeneidad social, en el sentido que emplea Antonio Cornejo Polar, llevándonos necesariamente al origen del conflicto: el encuentro, en Cajamarca en el año de 1532, entre el Inca Atahualpa y el fraile Vicente Valverde. Encuentro que es la causa primera del indigenismo peruano e ilustra la categoría de heterogeneidad básica o primaria, entendida como ese primer contacto de culturas cerradamente diferenciadas. Heterogeneidad que se preserva en la categoría de clase, como lo deja ver Aréstegui a través de la estructura social en la que se inscriben sus personajes, puesto que son determinados contextualmente por ésta a pesar de los procesos de mestización étnica de los siglos posteriores al encuentro de Cajamarca. Por tanto, lleva a una producción de signos que hablan del "otro" bajo una óptica totalmente prejuiciada. Narciso Aréstegui, a través del narrador de su novela (que resulta abiertamente alter ego del autor), exclama:

${ }^{1}$ Estudios realizados sobre el tema del origen de la novela en el Perú demuestran que no es ésta la primera novela del país. No siendo aquí el espacio propicio para el desarrollo de esta temática, remito al ensayo de Marcel Velázquez: "Los orígenes de la novela en el Perú: paratextos y recepción crítica (1828-1879)” (2010: 75-101). 
¡Y aún se abusa del sufrimiento de esta raza desgraciada! Apartando la vista de su indigencia, se les escarnece llamándolos infelices, porque callan, sufren y obedecen, quizá por la fuerza, puesto que no pueden dejar de reconocer cuando están verdaderamente obligados; y no se procura aliviar siquiera la triste suerte de sus hijos, mediante una mediana instrucción suficiente tal vez para su ventura!...

Nuestra misión al tomar la pluma, es la de manifestar las miserias de esa porción de individuos de nuestra especie, reclamando la igualdad ante la ley, de que deben gozar con todos, y que está en la CARTA.

La de los legisladores es sin duda echar una ojeada paternal sobre la suerte de los pobres indios (Aréstegui, 1974: 235-236).

El discurso de Aréstegui, si bien aboga por los indios, no es, ni representa, la voz del indio manifestándose, sino la de su "otredad": la del "misti". El blanco que se compadece de él pero que, contradictoriamente, cuando el indio se ve forzado a hablar en el texto éste le presta su habla, su "castilla", no le concede el uso de su propia voz. Detalle que permite apreciar la diferencia como una condición heterogénea y no como un proceso de mestizaje.

En suma y atendiendo al concepto categórico de heterogeneidad, podemos decir que Elpadre Horán es un escorzo social donde los indios representan el mundo lumpen, el basamento de una columna de clases en la que los blancos, quienes hablan en "castilla", no están exentos de diferencias, sino que, por el contrario, son violentamente marcados por su ralea (sumatoria de linaje y riqueza).

La novela de Aréstegui, como otras de la época, no es un ejemplo de perfección formal, ya que lleva en no pocas ocasiones más a servir como medio que como fin; es decir, se compromete con lo literal y descuida lo literario. En los países latinoamericanos estas obras acusan una influencia determinante de la novelística europea, pese a ello su valor es sustantivo en un proceso literario que 
no ha dejado de existir en nuestros días, me refiero a una literatura imbricada fuertemente con su inmediatez histórica. Sustento esta afirmación en dos puntales: el juicio crítico de Antonio Cornejo Polar y el capítulo segundo de la propia novela.

Veamos la consideración que hace Cornejo Polar de El padre Horán en su Historia de la literatura del Perú republicano:

La filiación de la novela es confusa tiene claras deudas con el costumbrismo [...], enfatiza algunos rasgos inocultablemente románticos [...] y refleja cierta influencia del realismo balzaciano (en referencia sobre todo a la comprensión de la novela como estudio de la realidad social). Ciertamente Elpadre Horán no realiza plenamente, ni mucho menos todos estos niveles pues es obvia la cortedad de sus alcances y las inseguridades de su trazo, pero sus diversas aproximaciones, y sobre todo su examen de los problemas del pueblo indio, le otorgan una evidente importancia en el proceso de la novela peruana. Su impacto en Aves sin nido así lo demuestra (37-38).

Por su parte, el segundo capítulo de la novela ejemplifica perfectamente el compromiso histórico de la obra cuando describe la terrible circunstancia de una familia paupérrima de indios: una de las hijas padece viruela y el hijo varón está ausente ocupado en trabajos inicuos propios de su condición social. El narrador nos hace entrar en su mísera "casita" y calar el frío serrano del Cuzco. Pinta un cuadro que, a pesar de tocar un filón de sensiblería, nos hace consternar ante una situación que se desborda de lo literario para tocar nuestra actualidad, pero sobre todo sirve para levantar la voz y reclamar, a nombre de los miserables, un estado de justicia. De esta manera el texto abandona su condición ficcional para abrir un intersticio desde el cual estas gentes, no ya los personajes de "papel" sino los actores de "carne y hueso" de la historia andina, surgen ante los ojos del lector: 
Parecerían triviales estos bosquejos de la vida de la gente pobre del Cuzco; pero no lo son, en verdad, para el que con ojo imparcial descubre en ella rasgos sublimes de amor y resignación.

Las quejas de esta clase infeliz no han sido escuchadas jamás sino por ella misma; y sus tristes acentos se apagan sin hallar otro eco que el que reflejan los negruzcos ángulos de sus pobres moradas.

A pesar de sus melancólicos pensamientos, los dos esposos de que hablamos, confiando en la Providencia soportaban sus males, murmurando apenas, un gemido para consolarse con él (Aréstegui, 1974: 231).

Avanzando en la cronología novelística del Perú del siglo XIX, dejando en su primera mitad a Narciso Aréstegui, nos encontramos con la obra y la persona de Clorinda Matto de Turner. Su novela insignia, Aves sin nido, comparada con El padre Horán, resulta mucho más frontal respecto a la denuncia de las inequidades sociales, de la corrupción de los que detentan el poder político y "divino" y, sobre todo, es mucho más contundente en la posición de su autora. Para ello, Clorinda Matto de Turner, se ve en la necesidad de redactar un proemio a la novela donde hace una declaración de principios, donde refrenda la plena conciencia que tiene sobre el poder de la obra literaria como un factor de construcción social. Escribe en términos que van de lo subjetivo a lo político:

Amo con amor de ternura a la raza indígena, por lo mismo que he observado de cerca sus costumbres, encantadoras por su sencillez, y la abyección a que someten a esa raza aquellos mandones de villorrio que, si varían de nombre, no degeneran siquiera del epíteto de tiranos. No otra cosa son en lo general, los curas, los gobernadores, caciques y alcaldes [...].

Repito que al someter mi obra al fallo del lector, hágolo con la esperanza de que ese fallo sea la idea de mejorar la condición de 
los pueblos chicos del Perú. Y aún cuando no fuese otra cosa que la simple conmiseración, la autora de estas páginas habrá conseguido su propósito, recordando que en el país existen hermanos que sufren, explotados en la noche de la ignorancia, martirizados en esas tinieblas que piden luz; señalando puntos de no escasa importancia para los progresos nacionales; y haciendo a la vez, literatura peruana (Klahn, 1991: 161-162).

El proemio para Aves sin nido no necesita mayor explicación respecto a la evidente presencia de la heterogeneidad como realidad y principio que mueve al acto literario en su autora. Heterogeneidad étnica, cultural e intelectual.

Antonio Cornejo Polar nos da dos directrices importantísimas para la comprensión de la obra en su trabajo: Aves sin nido: indios, notables y forasteros, cuando se refiere a la intención de la novela de presentar y exponer dos factores determinantes en su estructura. Anota el crítico que hay una desigualdad entre el aspecto técnico y su "elaboración" conceptual, lo que viene a confirmar un uso comprometido de la forma literaria, es decir, un uso que sirve a un actuar político desde un estamento ideológico correspondiente:

Aves sin nido se presenta ante el lector como un texto escindido en dos niveles: uno de representación, que a la vez busca una pluralidad de objetivos (básicamente mostrar la realidad y enjuiciarla), y otro de exposición de algunas opiniones que se constituyen como tesis del relato. La realización narrativa de la novela obedece íntegramente a este esquema [...].

En el proemio muestra Clorinda Matto una notable seguridad en el trazo de los propósitos que animan a la narración y un muy súbito nivel de autoconciencia: entendida la novela como un serio y trascendente ejercicio de moral social (2005: 152; cursivas mías).

Trazada ya la línea de partida con El padre Horán y Aves sin nido y ubicados en este nicho de tiempo que ofrece el siglo XIX peruano, 
el paso al siguiente siglo nos obliga a considerar una figura altamente representativa de la intelectualidad, no sólo del Perú sino de Latinoamérica, en quien se engarzan ambos tiempos: Manuel González Prada (1844-1918).

González Prada, personalidad que preludia a José Carlos Mariátegui, perteneció a una familia de la aristocracia peruana: los González y Prada; sin embargo, rompe con los valores y principios de su clase, indicio de ello está en la reducción de su apellido a González Prada, y como dice Cornejo Polar:

Pendularmente con respecto a su origen, González Prada, optó por el ateísmo, el positivismo y el anarquismo. En lo literario combatió con violencia contra el mantenimiento de la tradición española, polemizó duramente con Palma e impulsó una literatura acorde con los postulados de la ciencia, literatura que se reconoce, mal que bien, bajo el nombre de realismo (1980: 48).

Manuel González Prada participó en el Círculo Literario de Lima (1886-1891) y hacia el final de su vida fue nombrado Director de la Biblioteca Nacional (1912-1918), único cargo público que aceptó. ${ }^{2}$ En 1885 , en su primera presentación pública, en el Ateneo y con motivo de la fundación del Círculo Literario, González Prada pronuncia una conferencia en la que aborda el tema de la literatura y la autenticidad. En esta pieza encontramos, particularmente en su parte conclusiva, afirmaciones que toman rumbo hacia lo que de otra manera, pero con el mismo espíritu, va a puntualizar Cornejo Polar. Cito un fragmento del discurso:

Vamos perdiendo ya el desapego a la vida, tan marcado en los antiguos españoles, y nos contagiamos con la tristeza gemebunda que distingue al indígena peruano.

${ }^{2}$ Para una visión mayor del trabajo de Manuel González Prada, vid. Augusto Tamayo Vargas, Literatura peruana, (s/f: 714-738) 
No hablamos hoy como hablaban los conquistadores: las lenguas americanas nos proveen de neologismos que usamos con derecho, por no tener equivalentes en castellano, por expresar ideas exclusivamente nuestras, por nombrar cosas íntimamente relacionadas con nuestra vida. Hasta en la pronunciación ¡cuánto hemos cambiado! (17). ${ }^{3}$

José Carlos Mariátegui, en los Siete ensayos de interpretación de la realidad peruana, se refiere a González Prada en términos que pueden muy bien apoyar la tesis que lo califica como predecesor tanto del mismo Mariátegui como de Cornejo Polar. Escribe el autor de los siete ensayos:

González Prada es, en nuestra literatura, el precursor de la transición del periodo colonial al periodo cosmopolita. Ventura García Calderón lo declara "el menos peruano" de nuestros literatos. Pero ya hemos visto que hasta González Prada lo peruano en esta literatura no es aún peruano sino sólo colonial. El autor de Páginas libres aparece como un escritor de espíritu occidental y de cultura europea. Mas, dentro de una peruanidad por definirse, por precisarse todavía, ¿Por qué considerarlo como el menos peruano de los hombres de letras que la traducen? ¿Por ser el menos espańol? ¿Por no ser colonial? La razón resulta entonces paradójica. Por ser la menos espańola, por no ser colonial, su literatura anuncia precisamente la posibilidad de una literatura peruana. Es la liberación de la metrópoli. Es, finalmente, la ruptura con el virreinato (2002: 227-228).

Manuel González Prada es indudablemente el antecesor más claro de los ensayistas del Perú del siglo XX, aunque él mismo nunca use el término ensayo para sus trabajos. A pesar de ello, Estuardo

${ }^{3}$ Para una mayor profundización en este punto, recomiendo el ensayo de Dorian Espezúa Salmón: "Manuel González Prada y el dilema de la lengua nacional" (2010: 29-47). 
Núñez los describe en los siguientes términos: "La variedad y actualidad de los temas, el punto de vista personal, la originalidad con que son presentados, la brevedad y el rigor, la ausencia de erudición agobiante, son características inconfundibles de esos escritos, acaso los primeros "ensayos" que se escribieron en el Perú (1965: 156).

Es necesario remarcar el sentido que tiene González Prada de la evolución del idioma (español del Perú) en tanto un constructo heterogéneo donde los elementos indígenas y castellanos se imbrican sistemáticamente y se definen en correspondencia sintáctica, léxica y semántica. Un idioma que responde efectiva y eficientemente a las necesidades comunicativas de una realidad "otra" que le obliga a su recomposición. Un idioma forzado a someterse a un proceso transcultural en respuesta a la condición de heterogeneidad histórica y social de sus hablantes. El idioma transcultural que permitirá más tarde la expresión literaria de autores como José María Arguedas.

Este trabajo no estaría completo si no se abre un espacio para mostrar el pensamiento contrario a la heterogeneidad, el que en este cambio del siglo del XIX al XX en el Perú sostiene la idea de una identidad unívoca recargada en el paradigma hispanizante y eurocéntrico. Dicho espacio lo dedicaremos a uno de los intelectuales de mayor erudición en el mundo iberoamericano de su tiempo: José de la Riva Agüero (a quien se equipara con Andrés Bello y Alfonso Reyes; además se ha dicho que es el par americano de Marcelino Menéndez y Pelayo).

En oposición a la postura de Manuel González Prada, encontramos en José de la Riva Agüero a un joven liberal que gira su pensamiento en su madurez hasta llegar a un conservadurismo radical católico. Peruanista notabilísimo, los títulos de sus obras demuestran su quehacer en este sentido: Carácter de la literatura en el Perú independiente (1905), La historia en el Perú (1910), El 
Perú histórico y artístico (1921) o Civilización peruana; época prehispánica (1937). Perteneció a la llamada Generación del 900, ${ }^{4}$ cuya característica principal, nos dice Víctor Andrés Belaúnde (quien también perteneciera al grupo), es: "mantenimiento de la fe católica como fuerza de cohesión y unidad social y apoyo a la iglesia como la institución mejor capacitada para continuar la admirable obra iniciada de asimilar la raza indígena a la cultura occidental" (Vid. Riva Agüero, 1962: XX). En Carácter de la literatura del Perú independiente, Riva Agüero, escribe un texto que viene a ser muestra ejemplar, desde el ejercicio analítico de la historia peruana, de los postulados de su generación:

La raza espańola trasplantada al Perú, degeneró de sus caracteres en criollismo. Algo de tal degeneración no fué privativo del Perú ni de la América, (y por consiguiente alcanzó también a España misma, como que fue resultado de su agotamiento físico y moral, por los terribles esfuerzos que se impuso en los siglos XVI y XVII y del cual todavía no ha acertado a salir); pero en gran parte obraron aquí circunstancias especiales. La influencia debilitante del tibio y húmedo clima de la costa, núcleo de la cultura criolla, el prolongado cruzamiento y hasta la simple convivencia con las otras razas india y negra; el régimen colonial que apartando de la vida activa, del pensamiento, de la guerra y del trabajo, favoreciendo el servilismo y la molicie, produjo hombres indolentes y blandos; tales fueron los factores principales que determinaron esa transformación (1962: 68-69).

No voy a emitir ningún juicio respecto a la afirmación de Riva Agüero, pues no es la intención de este trabajo; no obstante, sí

${ }^{4}$ Pertenecieron a la Generación del 900, además de José de la Riva Agüero y Víctor Andrés Belaúnde, los hermanos Francisco y Ventura García Calderón, Julio C. Tello, Felipe Barreda, Juan Bautista, Fernando Tola y Luis Fernán Cisneros. 
quiero resaltar su perspectiva en un marco de relaciones transculturales y heterogéneas, mostrando su posición como icono del grupo hegemonizante que, como también se observa en Belaúnde, no vislumbra la unidad peruana como el horizonte plural de "todas las sangres".

Este carácter criollo (cuyo más fiel representante es el limeño) predomina en toda la literatura peruana, lo mismo en la Colonia que en la república; lo mismo en Caviedes que en Segura, en Palma y Pardo; y en virtud de su superioridad anula casi por completo la influencia que ha podido ejercer el genio de la raza indígena.

[...] Luego por imitación deliberada y dilettantismo, ha entrado también el elemento indígena en proporciones diversas, en unas pocas obras.

Por lo que toca a la raza negra, como no puede reconocérsele nada que se asemeje siquiera a un ideal literario, y como sólo por excepción y en débil grado ha influido por la herencia sobre lo que en el Perú han cultivado la literatura, parece innecesario ocuparse de ella (71).

Desde una posición descontextualizada se puede caer en un juicio equívoco respecto a la visión que ofrece José de la Riva Agüero e incurrir en el vicio de estereotipar en bueno y malo, cuando de lo que se trata es de construir un horizonte integral para comprender determinada realidad, en este caso nuestra, que antecede y nutre al concepto de heterogeneidad formulado por Antonio Cornejo Polar. Por ello y en atención a la comprensión de los conceptos de Riva Agüero, habrá que situarlos en el marco de la crítica de arte en el Perú de los siglos XVIII y XIX. Se hace esto porque es de justicia inexorable marcar el rigor de pensamiento de Riva Agüero, un rigor similar al que demuestra Alfonso Reyes al escribir El deslinde. Un rigor que pone una frontera y descalifica la afición diletante del artista y del crítico y hace de estos quehaceres un ejercicio de cono- 
cimiento profundo y de reflexión acuciosa, independientemente de que llegue a resultados equívocos o refleje prejuicios ideológicos. Así, en sentido de retrospección, recuperaremos elementos del ejercicio de esta crítica artística que se consolida en su rigor intelectual con pensadores como Jose de la Riva Agüero. La crítica de arte peruana del XIX evidencia un sentido de clase, en un primer momento, y produce una línea de nacionalismo impregnado de sentido social, posteriormente, que alcanzará, prospectivamente, a las ideas del propio Cornejo Polar. Por otro lado, informa de la importancia fundamental de la publicación periódica como un medio de divulgación en los siglos XVIII y XIX y conecta con el sentido que éstas adquieren en el siglo XX. Para efecto de esta retrospectiva, se toma como referente central al pintor decimonónico Francisco Lazo, obedeciendo a que la literatura y su crítica no son ajenas al acontecer de todas las artes.

La crítica de arte en Lima (que es como decir todo el Perú), a finales del siglo XVIII y hasta bien entrado el siglo XIX, fue una actividad de diletantes, como apunta el académico y crítico de arte de la Universidad Nacional Mayor de San Marcos, Manuel Marcos Percca:

En las posesiones españolas de ultramar, al finalizar el siglo XVIII, el comentario que dio cuenta del «estado de desarrollo del teatro, la poesía y la música» o resaltó los «méritos» cualitativos de diversos objetos de arte, fue una práctica que se redujo a un núcleo de personas que tuvo como rasgo diferenciador el interés por divulgar a través de medios impresos, todos estos criterios perceptivos a fin de contribuir al «sano entretenimiento» e «ilustración» de sus lectores o a la "promoción del buen gusto» entre aquellos.

Así se puede afirmar que los razonamientos y juicios sobre los objetos culturales y artísticos en nuestro medio nacieron siendo un ejercicio de criollos instruidos con aspiraciones culturales y 
económicas emparentadas a ciertos requerimientos moderno-burgueses (Percca, inédito: 1).

No obstante, a mediados del siglo XIX, esta circunstancia particular de la crítica dio un giro impetuoso hacia un ejercicio que planteó reclamos de mayor envergadura, ligados a la construcción republicana del Perú. Uno de los mayores protagonistas en este cambio fue el célebre pintor Francisco Lazo (Vid. Lazo, 2003). Deslindados del poder público y sin más elementos de apoyo que su propia opinión, este grupo de críticos publicó una serie de artículos que comenzaron en 1850 y terminaron hasta que irrumpió la guerra con Chile (1879-1883). Los espacios que acogían estos artículos eran órganos de sociedades literarias y culturales o bien periódicos de capital privado. La postura que proponían era a favor del progreso y de la cultura nacional, entendida como la republicana. Estos textos muchas veces alcanzaban dimensiones de furibunda crítica contra las tiranías liberales y no frenaban en los temas del arte y la cultura sino que se desbordaban y denunciaban los vicios del poder público (caudillismo, clientelismo, autoritarismo, elitismo) en una sociedad marcada por la barbarie, la inseguridad y la miseria. Manuel Marcos, se refiere a este momento y afirma:

Basta hojear los artículos del pintor Francisco Lazo en la Revista de Lima (1859-1862) o los que se generaron a raíz de la indiferencia de las autoridades ante las "primeras exposiciones públicas de pintura» de 1860 y 1861, o por la desatención estatal a las innumerables iniciativas y proyectos de formar escuelas y talleres públicos para la enseñanza del dibujo y la pintura. Los autores de esta crítica buscaban hacer realidad la república imaginada y una de las maneras de dicha búsqueda fue la preocupación ideológica por el desarrollo nacional, la educación y civilización. Atrás había quedado cualquier deseo de operar en el campo de las alegorías y los significantes lógicos (las retóricas) (Percca, inédito: 7). 
Encontramos en este grupo de críticos una semilla ideológica y de trabajo para los intelectuales posteriores, como Mariátegui y Cornejo Polar. Cuando el autor de Escribir en el aire se refiere a la crítica como una posibilidad de construir la historia social, tácitamente rinde un homenaje a este grupo de "activistas" culturales. Continúa Manuel Marcos:

Por esto no fue extraño que el individuo crítico demandase públicamente al Estado auspiciar la formación de artistas en las escuelas de las metrópolis más importantes, para que cuando retornen al Perú puedan introducir los valores culturales de la modernidad y "con esto se eduque al pueblo», o exigiese a diferentes gobiernos que posibiliten el "progreso de las Bellas Artes en el país» por considerar a estas como medio capaz de integrarnos a las naciones verdaderamente civilizadas y cultas», u opte por apoyar los proyectos civiles (1872-1876) de construir un orden capaz de sentar las bases para un desarrollo cultural sostenido que, entre otras cosas, permita la dignificación de los artistas e intelectuales «independientes», junto con la posibilidad de que estos ejerzan un rol activo en el diseño de la imagen nacional de la República. Entre 1850 y 1878 la crítica estuvo aparejada con una función práctica, política y moral. Deseaba operar en el campo de la gente y los objetos (7-8).

Más que un mapa social e histórico del Perú del siglo XIX en su estamento cultural republicano, son las palabras del propio pintor Francisco Lazo las que pueden darnos una clara idea de la situación que ya hemos vislumbrado en las afirmaciones de Manuel Marcos. En la Revista de Lima, en su edición del 15 de marzo de 1861, podemos leer:

Ya que en el Perú un pintor no puede ejercer su profesión, que le sea siquiera permitido pensar en el tayer $[$ sic] [...]. Ya que no puedo pintar, escribiré siquiera. Verdad es que el pintar y el escribir, 
para nuestro muy respetable público, es exactamente lo mismo. Si los cuadros tienen poca importancia, tal vez lo tengan menos los escritos. Pero en igualdad de circunstancias, es preferible manejar la pluma que no el pincel, por ser más económico el escribir que pintar. Además el escribir en la Revista no es un trabajo enteramente perdido, puesto que un artículo inserto en ella siempre tendrá los honores de ser leído por la mayor parte de los redactores y de algunos buenos patriotas que, después de erogar un peso mensual, practican la acción heroica de revisar nuestro periódico.

Nosotros que en América no vemos sino las obras que nos vienen de Europa, nos formamos muchas veces una idea falsa de los caracteres de sus autores. Nuestra imaginación poetiza casi siempre al grave corregidor de costumbres con sus piezas dramáticas, al melancólico poeta, al pintor sublime y al músico sentimental - Pero ¡Oh Bufon! Cuántas veces el estilo no es el hombre (203-207).

Como podemos apreciar, queda refrendado que la crítica literaria, como la del resto de las artes en el Perú, se imbrican fuertemente con la realidad nacional. El artículo de opinión primero y posteriormente el ensayo serán instrumentos de gran utilidad para la conformación de las ideologías, de las identidades y de la participación política entendida en su más alta significación. Por eso su estudio es, en la indagación sobre la peruanidad y el ser de la crítica literaria del Perú, imprescindible; ya que propone una peruanidad heterogénea que en el aspecto intelectual permite la interacción, no siempre fácil ciertamente, de ideologías como las que sostienen José de la Riva Agüero y Manuel González Prada.

Antonio Cornejo Polar se verá inmerso en este contexto por medio de la línea histórica de "peruanidad". Línea en la que es imprescindible señalar como el mayor ejemplo de este quehacer reflexivo a José Carlos Mariátegui y la revista Amauta, donde la producción del arte, la participación política, el estudio social, la indagación antropológica o el pensar filosófico se tocan, se entrecruzan 
y se complementan. Amauta y Mariátegui son fuentes de máxima inspiración para el autor de Escribir en el aire.

Mencionar la revista Amauta implica traer "a la mesa de discusión" todo un mundo de actividad intelectual y de creación artística que se desenvuelve a principios del siglo XX en el Perú (no sólo en Lima, como en los siglos anteriores, sino paralelamente en algunas otras ciudades como Puno y Cuzco). Vale mucho la pena hacer un recorrido, aunque sea "a vuelo de pájaro", por esos años de 1905 a 1930, periodo que Cynthia Vich marca como crucial en la reflexión en torno a la literatura que se hace en este país andino. Además, porque las publicaciones que a continuación se mencionan son antecesoras directas de la Revista de Critica Literaria Latinoamericana, fundada en Lima en 1973, por Antonio Cornejo Polar, y con vigencia hasta la fecha actual.

En su estudio sobre el Boletín Titikaka, realizado bajo la asesoría de Antonio Cornejo Polar, Cynthia Vich presenta un panorama del pensamiento crítico peruano en los primeros ańos del siglo XX:

El periodo entre 1905 y 1930 fue la época en que cuantitativa y cualitativamente se discutió con mayor intensidad el campo de la literatura peruana y su inserción dentro del marco más vasto del contexto histórico-social del país. Es decir, fue durante las primeras tres décadas del siglo XX cuando los términos del debate nacional se reajustan sobre la base de cambios provenientes de distintas esferas. Durante ese periodo se sucedieron diversas aproximaciones que se plantearon no sólo una aprehensión global de la literatura sino que también supieron utilizarla para la presentación de sus concepciones sobre la identidad nacional (2000: 43).

Es muy importante la observación que hace Cynthia Vich porque en ese espíritu y en ese proceso se va a afincar la reflexión de Cornejo Polar. Este periodo corresponde también al de la edición de dos revistas de fundamental importancia para el proceso crítico li- 
terario y cultural de Perú y de toda Hispanoamérica: El Boletín Titikaka (1926-1929) y la ya citada Amauta (1926-1930). Publicaciones que vienen precedidas desde Lima por El Mercurio Peruano (1791-1794) — que toma como base ideológica la «Declaración de los derechos del hombre y del ciudadano»- y la Revista de Lima (1859-1863) — que va a albergar a intelectuales de la talla del sacerdote ilustrado y liberal Francisco de Paula González Vigil-. Desde Puno podemos citar a La Tea (1917-1919) del grupo Bohemia Andina y también debe considerarse a Colónida "Revista quincenal de Literatura, Arte, Historia y Ciencias Sociales" (1916), de Abraham Valdelomar; esta última animada por una estética y una estilística renovadoras. Las publicaciones que anteceden a Amauta y al Boletín Titikaka, no sólo son precursoras en términos editoriales, sino que fermentan un espíritu de intelectualidad crítica fuertemente comprometido con la problemática social, espíritu que se recoge y encuentra plenitud tanto en Amauta como en el Boletín.

$\mathrm{Al}$ seguir con la presentación del horizonte intelectual de Perú en aquellos prematuros años del siglo XX, Cynthia Vich se enfoca en el problema que nos ocupa: la relación cultural de lo único y lo múltiple; es decir, la disyuntiva entre una identidad subsidiaria del modelo hispanista y eurocéntrico o una identidad heterogénea de "todas las sangres". Al llevar este problema a la literatura podemos hablar de una expresión unívocamente esteticista y otra cuya estética permite los sentidos heterotópicos del texto. Nos dice Vich:

A la filiación completamente hispanista del concepto de nacionalidad (y por consiguiente, de «literatura nacional») de José de la Riva Agüero, se opusieron otras como la de José Gálvez, Federico More o Luis Alberto Sánchez. Estas desarrollaron las distintas variantes de la entonces popular ideología del mestizaje [...].

Lo que quiero enfatizar en este punto es que durante este periodo la intelectualidad peruana tenía en la literatura su instrumento más valioso no sólo para conocer el Perú, sino sobre todo 
para elaborar la imagen de peruanidad que se iba a proponer mucho más allá del campo específico literario [...].

Todavía en las primeras décadas del siglo XX en el Perú, la literatura conservaba cierto carácter público (en el sentido de no especializado) que le aseguraba una posición de legitimidad en la discusión sobre los proyectos de transformación social (44).

En este escenario resulta fundamental el Boletín Titikaka por los factores que lo determinan: a) su espíritu continentalista; b) las circunstancias de su edición y circulación desde una pequeña ciudad sin universidad; $c$ ) su impacto internacional; d) su contenido de orden literario que hace convivir la producción peruana e hispanoamericana con la producción local, y e) su postura frente al indigenismo. Factores que hacen del Boletín una publicación equiparable con Amauta.

El Boletín Titikaka estaba dirigido por los hermanos Peralta: Arturo y Alejandro. Arturo, mejor conocido bajo el pseudónimo de Gamaliel Churata, se va a convertir en uno de los grandes poetas del Perú. ${ }^{5}$ En su obra El pez de oro escribe unas líneas altamente reveladoras de la visión que él y seguramente también un grupo de escritores e intelectuales de la época mantenían sobre la obra literaria. Afirma Churata:

En las letras, en la palabra, que se compone de letras, en el lenguaje que se edifica con palabras, si escritas, se contiene el órgano de expresión de una literatura; por lo que el punto de partida de toda literatura (y de todo hombre) está en el idioma que la sustancia. Los americanos no tenemos literatura, filosofía, derecho de gentes, derecho público, que no sean los contenidos en los idiomas vernáculos, ninguna literatura escrita y sólo leyendas

${ }^{5}$ También había participado en el grupo Bohemia Andina y su revista La Tea, donde publicaba bajo el pseudónimo de Juan Cajal. No obstante, en lo sucesivo me referiré a este escritor con su pseudónimo más conocido: Gamaliel Churata. 
en literatura vocal, ciencia hablada, que se guardaron mediante wayrurus, chispas de oro, khachinas de ónix, encantadora simbología y nemotecnia que empleaban los harawikus para representar sus epopeyas en los grandes días cívicos del Inkario y conservar así las creaciones específicamente literarias, —bobez aparte- en que no fue raquítico el ingenio de sus poetas y filósofos. El caso es que nos empeñamos en tenerla valiéndonos de una lengua no kuika: la hispana. Y en ella borroneamos "como indios", aunque no en indio, que es cosa distinta. Y aun así esto será posible sólo si resultamos capaces de hacer del español —solución provisional y aleatoria - lo que el español hizo de nosotros: mestizos — para España también aleatoria y provisional solución-. Pero un mestizo puede germinar en nueve meses y salirse toreando. Un idioma no. Los idiomas vienen de un tiempo de trino: el de lactancia del Pithencantropo; se mezclaron después, contendieron con voces a ellos ajenas, asimilaron unas, chaKCháronlas, escupieron otras, en fin, las amañaron a la índole de su gorjeo y a la idiosincrasia de sus medios lonríngeos en no pocos siglos (2007: 9).

Las frases de Churata develan perfectamente el espíritu de la época y la visión que entonces se tiene de la identidad. Por medio de una lectura interlineal podemos sentir la presencia de la categoría de heterogeneidad, la que se establece como un vaso comunicante entre Amauta y el Boletín. En la presentación que hace José Carlos Mariátegui para el primer número de Amauta (septiembre de 1926), se lee:

Esta revista en el campo intelectual no representa un grupo. Representa, más bien, un movimiento, un espíritu. En el Perú se siente desde hace algún tiempo una corriente, cada día más vigorosa y definida, de renovación. A los fautores de esta renovación se les llama vanguardistas, socialistas, revolucionarios, etc. La historia no los ha bautizado definitivamente todavía. Existen entre ellos algunas discrepancias formales, algunas diferencias psicológi- 
cas. Pero por encima de lo que los diferencia, todos estos espíritus ponen lo que los aproxima y mancomuna: su voluntad de crear un Perú nuevo dentro del mundo nuevo. La inteligencia, la coordinación de los más volitivos de estos elementos, progresan gradualmente. El movimiento — intelectual y espiritual— adquiere poco a poco organicidad. Con la aparición de Amauta entra en una fase de definición (1926: 1).

Para el grupo Orkopata, ${ }^{6}$ y desde luego para el Boletín Titikaka, José Carlos Mariátegui fue un referente ideológico fundamental, esto se verá reflejado en el último número del Boletín que está dedicado a él. Además, Gamaliel Churata fungió como agente regional de la revista Amauta.

Al igual que Puno, el Cuzco se va a convertir en un centro de publicaciones muy activo en esos momentos. En un contexto de violencia universitaria y polémica acalorada sobre la vida social y política, de inquietud indigenista e influencia del pensamiento de izquierda, surgen en la ciudad algunas revistas que son como "corriente de aire fresco" en una atmósfera universitaria enrarecida de conservadurismo. Se enfrentan allí los eternos polos en conflicto de la historia social: conservadores y liberales.

6 "El Grupo Orkopata estuvo integrado por intelectuales y artistas residentes en el departamento de Puno. El nombre del Grupo proviene del lugar donde se reunía de manera informal para llevar a cabo sus actividades. Su informalidad consiste en el hecho de que no era un grupo legalmente constituido, con ingresos propios y actas que registraran sus actividades. Por esta razón, es difícil saber quiénes fueron realmente sus integrantes. Existen varias versiones sobre el número de sus miembros que dependen de la fragilidad de la memoria, de la voluntaria inclusión de ciertos nombres famosos para darle mayor prestigio al Grupo o de la exclusión de otros para restarles el reconocimiento que posteriormente alcanzaron. Sin embargo, todas ellas coinciden en señalar que Gamaliel Churata [Arturo Peralta] fue el organizador y responsable del Grupo y que las reuniones se llevaban a cabo en su domicilio" (Zevallos Aguilar, 2002). 
Hago un recuento de la actividad intelectual y las publicaciones del Cuzco: Roberto Latorre Medina funda la revista Kosko (19241925), dos años antes de que Churata y Mariátegui fundaran las suyas, que se encaminó por los mismos rumbos que siguieron el Boletín y Amauta; en ella colaboraron Mariátegui, José Sabogal y también el fundador del APRA, Víctor Raúl Haya de la Torre. Le suceden Kuntur (1927), de Román Saavedra (Eustakio Kallata) y Julio Torres, y la revista Pututo (Revista oral de arte, crítica y polémica), que edita el grupo Ande. Tanto Kosko como Kuntur, se vieron preludiadas en el Cuzco por la revista La sierra, a cargo del grupo de influencia anarquista que llevó a cabo la huelga universitaria de 1909 (bajo la inspiración de Ángel Vega Enríquez) que seguía una línea indigenista a tono con las publicaciones ya citadas. Para cerrar este punto debe recordarse Albores, revista que ve luz pública el mismo año que Kuntur, editada por un grupo de mujeres feministas de izquierda, estudiantes de la Universidad de Cuzco, entre las que figuraban: Concepción Ramos, Carmela González Gamarra, Lucrecia Núñez de la Torre, Martha Alicia Yépes, Rosa Rivero, Teresa Loayza y Mercedes Quintanilla.

Todas estas revistas, incluidas el Boletín y Amauta, fueron los espacios de construcción ideológica tanto en lo político como en lo estético y hondando en el proceso nacional hacia un "Perú de todas las sangres" se hermanaron universalmente con las grandes Revoluciones del momento: la mexicana y la rusa. Así, se inscriben en un universalismo renovador de fuerte espíritu latinoamericano en donde las artes - a la manera del muralismo mexicano, el indigenismo plástico peruano o las narrativas indigenistas, proletarias y campesinas - van hombro a hombro con la reflexión y la acción solidariamente social. ${ }^{7}$ Fuera del circuito de revistas, pero en ese ámbito de actividad intelectual y política (usando el término "polí-

${ }^{7}$ Para una mayor comprensión de la relación con los movimientos revolucionarios citados, puede consultarse al artículo que sobre la Revolución Mexicana que 
tica" en su más amplio sentido), se encuentra el nexo "revolucionario americano" explícitamente expuesto en la conferencia titulada: Interpretación de la Revolución de Trujillo, que Ciro Alegría dicta a los jóvenes de la FAJ (Federación Aprista Juvenil). La conferencia fue publicada en Acción Aprista, edición correspondiente al 28 de julio de 1934. En ella, Ciro Alegría se refiere a la Revolución Mexicana y la relaciona con la Revolución de Trujillo en estos términos:

La Revolución de Trujillo no tiene precedentes en Indoamérica como movimiento ideológico [...]. Aún la Revolución Mexicana fue planteada un tanto demagógicamente. Careció de definidas premisas previas. El zapatismo, auténtica expresión del sentido más aguzado de las masas respecto a la revolución apenas alcanzó a gritar «Tierra y libertad». Pero no delineó ningún plan previo. Y así los otros bandos revolucionarios aztecas, excepción hecha del "villismo», cuyo estado mayor ignoraba el sentido de la lucha planteada. Ya en el gobierno, por eso, la revolución mexicana ha accionado en forma bastante desordenada, sin que por esto pretendamos quitarle validez renovadora (2004: 11-12).

En este marco de intelectualidad, los años veinte en el Perú ven realizar un trabajo que, liberándose de los prejuicios de imprecisión, convencionalismo e impresionismo de las perspectivas tanto conservadoras como de innovación modernista, lleva los estudios literarios a un rigor y seriedad que logra ponerlos "a tiempo con su tiempo", como dijera Ortega y Gasset. Se incursiona en los nuevos métodos de investigación literaria y se amplía el corpus hacia obras perfiladas como universales y vanguardistas. Destaca en este ámbito Víctor Llona (1886-1953), particularmente por su estudio sobre James Joyce: I don't know what to call it but it's mighty unlike

publicó el Dr. Atl, en el número tres de Amauta, correspondiente a noviembre de 1926. 
prose (París, 1929). Veamos un fragmento que da una idea clara sobre esta crítica:

Un conjunto de palabras en papel de actores teatrales — no sólo del inglés sino de muchas lenguas, vivas y muertas emergen aquí en tumultuoso y dramático ballet con acompańamiento de orquesta filarmónica, mientras que los ojos de los espectadores son intermitentemente deslumbrados y sosegados por el gran despliegue de colores que recorren toda la pródiga gama de una paleta de pintor. Todas las «palabras» con sus respectivas indumentariasalgunas reconocibles a primera mirada, otras indescifrables en su nueva apariencia, tal vez por una premeditada deformación de su legítima vestimenta- (Llona, s/f: 58).

Nótese que Víctor Llona conceptualiza el lenguaje como un conjunto de elementos dramáticos, musicales y plásticos, lo que recuerda en gran medida a Vicente Huidobro. En su texto sobre Joyce, el peruano se adelanta a la visión que Umberto Eco tendrá sobre la obra del dublinense ( $C f$. Eco, 1992: 5).

Es imposible aquí, por motivo de espacio, hacer un inventario del trabajo crítico que se ubica entre los años veinte del siglo pasado y la estancia de Antonio Cornejo Polar en la Universidad de San Marcos. Sin embargo, sí es imprescindible recordar a Alberto Escobar (1929-2000), sin duda uno de los puntales estudiosos sobre la modernización de los estudios literarios en el Perú y el antecedente inmediato de Antonio Cornejo Polar. Doctorado por la Universidad de Münich, realizó estudios de lingüística en la Universidad de Florencia y de filología en la de Madrid. Dos testimonios nos pueden ilustrar perfectamente sobre la importancia de Escobar: el primero, de Marco Martos Carrera, actual presidente de la Academia Peruana de la Lengua; el segundo, de Tomás Escajadillo, su alumno sobresaliente. Escribe Marco Martos en el portal de personajes sanmarquinos: 
[...] se desarrolló en Alberto Escobar una preocupación por la lengua no solamente como instrumento de comunicación, compleja trama de relaciones entre el emisor y receptor, sino como expresión social. En ese sentido su libro Lenguaje y discriminación social en América Latina (1972) es particularmente valioso, porque ofrece un marco teórico importante que ayuda a comprender el panorama lingüístico peruano y procura seńalar derroteros para encaminar mejor la enseńanza de las lenguas en el Perú (internet).

Por su parte, Tomás Escajadillo describe la relación que su maestro y Antonio Cornejo Polar mantienen en la "Universidad decana de América":

En varias oportunidades, he hablado de la "conmoción" y el rigor que trajo de Europa Alberto Escobar a los estudios literarios en San Marcos. Si Escobar, mi maestro, fue el gran innovador de la década del 50 y la primera mitad de la década siguiente, Cornejo Polar toma la posta inmediata en gran parte porque Escobar comenzó a interesarse más en la lingüística que en la literatura (incluso formalmente era profesor del Departamento de Lingüística) (1998: 41).

Alberto Escobar representa un paradigma de modernidad teorética y de rigor académico que será continuado por Cornejo Polar. Es impensable creer que sin un rigor que norme la reflexión se puede formular una propuesta crítica como la que hace Cornejo en torno al concepto categórico de heterogeneidad. Cierra este trabajo un factor capital en la construcción del concepto de heterogeneidad: la relación de Antonio Cornejo Polar con José María Arguedas. Este punto final puede muy bien ser la síntesis de todo lo que se ha dicho hasta aquí. Esto porque, Arguedas en la creación literaria y Cornejo Polar en la crítica, significan una síntesis de lo que en su campo se ha hecho y, a la vez, impulsan un desarrollo hacia nuevas 
problemáticas en su respectivo quehacer. Esta relación fundada en el estudio se fortalece con un acontecimiento particular: el primer encuentro de narradores en Arequipa.

La relación de Cornejo Polar con la obra del andahuaylino se da por medio de la incursión reflexiva, profunda y vívida. No obstante, la dimensión personal que tiene Arguedas para nuestro crítico se puede averiguar con el testimonio de Tomás Escajadillo, quien recuerda: "La muerte de Arguedas, a fines de 1969, lo marcó humanamente y como crítico" (Escadajillo, 1998: 42).

En su papel de director de la Casa de la Cultura de Arequipa, Antonio Cornejo Polar convoca al Primer encuentro de narradores peruanos, evento al que Arguedas calificaba como "un milagro de la luz arequipeńa”. Entre los participantes estaban: Oswaldo Reynoso, Carlos Eduardo Zavaleta, Eleodoro Vargas Vicuña, Ciro Alegría, José María Arguedas, Arturo Hernández, José Miguel Oviedo, Tomás Escajadillo, Sebastián Salazar Bondy, Alberto Escobar y Antonio Cornejo Polar. De este "estadio literario" dijo Carlos Eduardo Zavaleta:

Ese cónclave no sólo fue la primera empresa de gran aliento de Cornejo [...], sino uno de sus más altos logros artísticos en el país. Más tarde hemos tenido otros encuentros nacionales y regionales, pero ésa fue la primera y única vez en que novelistas y cuentistas de la talla de Ciro Alegría y José María Arguedas dialogaron y debatieron juntos con representantes de las nuevas generaciones de literatos (Apud. Escajadillo, 1998: 182-183).

Para Cornejo Polar tuvo un impacto decisivo el evento. Raúl Bueno Chávez lo aprecia así: "Es ahí donde, durante su intervención central, el joven Cornejo Polar esboza las líneas centrales del campo al que dedicará después la mayor parte de su vida intelectual - la heterogeneidad literaria y cultural de sociedades en conflicto" (Bueno Chávez, 2004: 140). 
En relación con la línea "cornejista" de estudio literario y cultural, me parecen fundamentales cuatro textos de José María Arguedas (no los únicos por cierto) que pueden relacionarse directamente con la heterogeneidad: La literatura Quechua en el Perú (1948), La novela y la expresión literaria en el Perú (1950), El complejo cultural en el Perú (1952) y su Confesión durante el encuentro de Arequipa (1965). Dos más de manera periférica pueden ser considerados: La clase media (1964) y La cultura: un patrimonio difíil de colonizar (1966). Todos ellos tratan la problemática (heterogénea, transcultural y acultural) de aquellas estructuras histórico-sociales que Raúl Bueno Chávez llama "sociedades en conflicto".

Sin embargo, son las palabras del propio Cornejo Polar las que evidencian su relación con el quehacer arguediano; en la introducción de su obra Los universos narrativos de José María Arguedas (1974), escribe:

Pero lo que sí resulta inexplicable es que quienes coinciden con Alejo Carpentier (para quien una de las misiones básicas del escritor latinoamericano es encontrar un lenguaje adánico, o un lenguaje capaz de decir lo nunca dicho) o con Carlos Fuentes (para quien el problema mayor de nuestra literatura es la carencia de un lenguaje auténtico y su primera obligación, por tanto, la de crearlo) no comprendan que la narrativa de Arguedas alcanzaba realizaciones extraordinarias dentro de una situación esencialmente compleja, confusa y quebradiza: el bilingüismo pluricultural de la zona andina, situación que representa el clímax de un estado común a toda Hispanoamérica y que, de alguna manera, define su realidad y su historia. «Esta experiencia ejemplar — decía Ángel Rama-, sobre todo porque es la más difícil que ha intentado un novelista en América (1997: 16).

La lucha con el lenguaje a la que alude Cornejo Polar es a la que se refiere Arguedas en relación con los relatos de Agua, los que leía dice el autor- a Adolfo Westphalen y a Luis Felipe Alarco y que 
escribió desde el rechazo a los relatos andinos de Enrique López Albujar y Ventura García Calderón. Cuenta Arguedas:

El relato les pareció muy bien. Yo lo había escrito en el mejor castellano que podía emplear, que era bastante corto, porque yo aprendí a hablar el castellano con cierta eficiencia después de los ocho ańos, hasta entonces sólo hablaba quechua [...]. Cuando yo leí ese relato, en ese castellano tradicional, me pareció horrible, me pareció que había disfrazado el mundo tanto casi como las personas contra quienes intentaba escribir y a quienes pretendía rectificar. Ante la consternación de estos mis amigos, rompí todas esas páginas. Unos seis o siete meses después, las escribí en una forma completamente distinta, mezclando un poco la sintaxis quechua dentro del castellano, en una pelea verdaderamente infernal con la lengua. Guardé ese relato un tiempo, yo era empleado de correos, estaba una tarde de turno y en una hora en que no había mucho público lo leí, y ese relato era lo que había deseado que fuera y así se publicó (Pinilla, 2004: 524; cursivas mías).

Esta muestra de construcción lingüística, literaria y cultural desde la sintaxis quechua en el castellano, "imbibición”, como lo califica Luis Alberto Ratto (Cf. 1977: 3-5) hace que la obra de José María Arguedas sea, indudablemente, el campo más vasto para los estudios literarios heterogéneos en la narrativa peruana, ya que en su obra se muestra de manera potenciada el proceso iniciado en Cajamarca por Atahualpa y el cura Valverde.

Todo el trabajo crítico de Antonio Cornejo Polar no se explica en ninguno de sus sentidos sin el antecedente fundamental y fundacional de la realidad peruana, entendida como "todas las sangres". Su formulación del concepto de heterogeneidad es un acto que implica, en primer lugar, el análisis crítico de la literatura pero, en segundo lugar, sostenido por una visión muy amplia que implica a la historia, la sociología y la antropología. La categoría de heterogeneidad que él devela ofrece una posibilidad de herme- 
néusis para estudiar en diferentes términos las obras literarias y los textos que tratan sobre este fenómeno cultural que es Latinoamérica: la confrontación entre las lenguas originarias y el castellano; el choque de la estructura sonora de la palabra hablada en una serie cultural autóctona y, por último, la estructura visual de la palabra escrita en otra serie cultural conquistatoria.

El horizonte que se expuso en este trabajo no tiene otro cometido que esclarecer cómo para Antonio Cornejo Polar la crítica literaria es un ejercicio cuyos procesos son multidisciplinares e implican elementos que se han ido forjando a lo largo del acontecer cultural de nuestros pueblos.

\section{Fuentes}

Alegría, Ciro, 2004, Novela de mis novelas, Lima, Pontificia Universidad Católica del Perú.

Aréstegui, Narciso, 1974, El padre Horán, Lima, Universo.

Bueno Chávez, Raúl, 2004, Antonio Cornejo Polar y los avatares de la cultura latinoamericana, Lima, Fondo Editorial de la Universidad Nacional Mayor de San Marcos, Humanidades.

Cornejo Polar, Antonio, Historia de la literatura del Perú Republicano, Lima, Ed. Juan Mejía Baca, 1980.

, 2005, Literatura y sociedad en el Perú: la novela indigenista. Clorinda Matto de Turner, novelista estudio sobre Aves sin nido, Índole y Herencia, Lima, CELACP- Latinoamericana Editores. et al., 1984, Vigencia y universalidad de José María Arguedas, Lima, Horizonte.

Churata, Gamaliel [Arturo Peralta], 2007, El pez de oro, Perú, Retablo Editores.

Eco, Umberto, 1992, Obra abierta, Barcelona, Planeta-De Agostini. 
Escajadillo, Tomás G., 1998, "Antonio Cornejo Polar: gran amigo, gran maestro, gran académico", en Perfil y entraña de Antonio Cornejo Polar, Lima, Amaru Editores.

Espezúa Salmón, Dorian, 2010, "Manuel González Prada y el dilema de la lengua nacional”, Contextos, núm. 1, Lima, UNMSM, pp. 29- 47.

González Prada, Manuel, s/f, Páginas libres / Horas de lucha, Venezuela, Biblioteca Ayacucho.

Lazo, Francisco, 1861, "Un recuerdo", Revista de Lima, Lima, 15 de marzo, pp. 203- 218.

, 2003, Aguinaldo para las señoras del Perú y otros ensayos, Lima, Museo de Arte de Lima.

Llona, Víctor, Obras narrativas y ensayos, disponible en www.comunidadandina.org/BDA/docs/PE-OC-0006.pdf (Consultado el 2/XI/2012).

Mariátegui, José Carlos, 1926, "Presentación de Amauta”, Amauta, Lima, septiembre, p. 1.

Núñez, Estuardo, 1965, La literatura peruana en el siglo XX (19001965), México, Editorial Pormaca.

Ratto, Luis Alberto, 1977, “Los problemas de la imbibición en José María Arguedas”, Runa, núm. 1, 1 mayo, Lima, Instituto Nacional de Cultura, pp. 3- 5.

Riva Agüero, José de la, 1962, Obras completas, t. I, Lima, Pontificia Universidad Católica del Perú.

Tamayo Vargas, Tamayo, s/f, Literatura peruana, José Godard (ed.), vol. II, Lima, pp. 714- 738.

UNMSM, www.unmsm.edu.pe/sanmarcos/biografia (consultado el 23/IX/2014) 
Velázquez, Marcel, 2010, "Los orígenes de la novela en el Perú: paratextos y recepción crítica (1828-1879)”, Revista Iberoamericana, núm. 37, Marzo, pp. 75- 101.

Vich, Cynthia, 2000, Indigenismo de vanguardia en el Perú: un estudio sobre el Boletín Titikaka, Lima, Pontificia Universidad Católica del Perú Fondo Editorial.

Zevallos Aguilar, Juan Ulises, 2002, Indigenismo y nación: Los retos a la representación de la subalternidad aymara y quecha en el Boletin Titikaka (1926-1630), Lima, Instituto Francés de Estudios Andinos y Banco Central de Reserva del Perú, disponible en www. cholonautas.edu.pe/modulo/upload/Zevallos (consultado el 8/ IX/2012)

(Artículo recibido el 15 de febrero de 2014; aceptado el 7 de mayo de 2014) 
